\title{
CORRECTION
}

\section{Measuring the cost of adverse events in hospital}

CMAJ has been made aware of an error that occurred in an article published in the Aug. 12, 2019, issue. ${ }^{1}$

In the first paragraph of the article, the last sentence read, "In 2014, the landmark Canadian Adverse Events Study reported adverse events in $7.5 \%$ of hospital admissions, with $37 \%$ of these events deemed preventable." It should have read, "In 2004, the landmark Canadian Adverse Events Study reported adverse events in $7.5 \%$ of hospital admissions, with $37 \%$ of these events deemed preventable."

CMAJ apologizes for the error.

- Cite as: CMAJ 2019 December 2;191:

E1340. doi: 10.1503/cmaj.191521

\section{Reference}

1. Lapointe-Shaw L, Bell CM. Measuring the cost of adverse events in hospital. CMAJ 2019;191:E877-8. 